\title{
Efficient Semitransparent Perovskite Solar Cells Using a Transparent Silver Electrode and Four-Terminal Perovskite/ Silicon Tandem Device Exploration
}

\author{
Dazheng Chen $\mathbb{D}^{\mathrm{D}},{ }^{1}$ Shangzheng Pang, ${ }^{1}$ Weidong Zhu, ${ }^{1}$ Hongxiao Zhang, ${ }^{1}$ Long Zhou, ${ }^{1}$ \\ Fengqin He, ${ }^{1,2}$ Jingjing Chang, ${ }^{1}$ Zhenhua Lin, ${ }^{1} \mathrm{He} \mathrm{Xi},{ }^{1}$ Jincheng Zhang $\mathbb{D},{ }^{1}$ \\ Chunfu Zhang $\mathbb{B D}^{1}{ }^{1}$ and Yue Hao ${ }^{1}$ \\ ${ }^{1}$ Wide Band Gap Semiconductor Technology State Key Laboratory, School of Microelectronics, Xidian University, \\ Xi'an 710071, China \\ ${ }^{2}$ Huanghe Hydropower Solar Industry Technology Co. Ltd., 369 South Yanta Road, Xi'an 710061, China
}

Correspondence should be addressed to Dazheng Chen; dzchen@xidian.edu.cn and Chunfu Zhang; cfzhang@xidian.edu.cn

Received 21 December 2017; Revised 27 March 2018; Accepted 11 April 2018; Published 3 May 2018

Academic Editor: Daruka Prasad

Copyright (C) 2018 Dazheng Chen et al. This is an open access article distributed under the Creative Commons Attribution License, which permits unrestricted use, distribution, and reproduction in any medium, provided the original work is properly cited.

\begin{abstract}
Four-terminal tandem solar cells employing a perovskite top cell and crystalline silicon ( $\mathrm{Si}$ ) bottom cell offer a simpler pathway to surpass the efficiency limit of market-leading single-junction silicon solar cells. To obtain cost-effective top cells, it is crucial to develop transparent conductive electrodes with low parasitic absorption and manufacturing cost. The commonly used indium tin oxide (ITO) shows some drawbacks, like the increasing prices and high-energy magnetron sputtering process. Transparent metal electrodes are promising candidates owing to the simple evaporation process, facile process conditions, and high conductivity, and the cheaper silver $(\mathrm{Ag})$ electrode with lower parasitic absorption than gold may be the better choice. In this work, efficient semitransparent perovskite solar cells (PSCs) were firstly developed by adopting the composite cathode of an ultrathin Ag electrode at its percolation threshold thickness $(11 \mathrm{~nm})$, a molybdenum oxide optical coupling layer, and a bathocuproine interfacial layer. The resulting power conversion efficiency (PCE) is $13.38 \%$ when the PSC is illuminated from the ITO side and the PCE is $8.34 \%$ from the Ag side, and no obvious current hysteresis can be observed. Furthermore, by stacking an industrial Si bottom cell $(\mathrm{PCE}=14.2 \%)$ to build a four-terminal architecture, the overall PCEs of $17.03 \%$ (ITO side) and $11.60 \%$ (Ag side) can be obtained, which are $27 \%$ and $39 \%$ higher, respectively, than those of the perovskite top cell. Also, the PCE of the tandem cell has exceeded that of the reference Si solar cell by about $20 \%$. This work provides an outlook to fabricate high-performance solar cells via the cost-effective pathway.
\end{abstract}

\section{Introduction}

In recent years, the emerging organic-inorganic hybrid perovskite material has been regarded as the promising candidate for the next-generation solar cells due to its strong optical absorption, long diffusion length, tunable bandgap, solution processability, low cost, and so on [1-5]. What is more striking is that the power conversion efficiency (PCE) of perovskite solar cells (PSCs) has exceeded 22\% [6] in 2016 since it first emerged in $2009(\mathrm{PCE}=3.8 \%)$ [7].
However, due to the relatively wide bandgap $(>1.55 \mathrm{eV})$, the photons in the infrared range $(>800 \mathrm{~nm})$ cannot be harvested by the perovskite material. One method to broaden the spectral response range and upgrade the performance of an established perovskite solar cell is to combine the low-bandgap $(1.12 \mathrm{eV})$ silicon $(\mathrm{Si})$ absorber under the perovskite cell to make a tandem solar cell. Simultaneously, the Si solar cells have dominated the photovoltaic markets for a long time, and the PCE record of the single-junction $\mathrm{Si}$ solar cell has reached $26.6 \%$ [8], but the relatively high manufactur- 
ing cost limits their wider applications. In recent years, the perovskite/Si tandem solar cells [9-24] have attracted increasing interest as they possess great commercial possibility in fabricating high-performance solar cells via the cost-effective pathway.

Generally, there exists three types of tandem architectures, the two, three, and four terminals. In the twoterminal architecture, the top solar cell is processed directly on the bottom solar cell. Since the top and bottom cells are electrically connected in series, it follows that current generation within both the top and bottom cells must be equal-a constraint known as current matching [9]. The first twoterminal perovskite/Si tandem cell appeared in 2015 and obtained a relatively low PCE of $13.7 \%$ due to the current mismatch issue and parasitic absorption [11]. By using a heterojunction bottom Si cell and optimized layer thicknesses, the PCE has been raised to $21.2 \%$ in 2016 [12]. After the caesium formamidinium lead halide perovskite was introduced in 2017, the record PCE further increased to $23.6 \%$ and also obtained good device stability [13]. However, the strict requirement of current matching constrains the bandgaps of the top and bottom cells, which limits the design flexibility and makes efficiency improvement more difficult. One approach is the three-terminal structures, in which two subcells are connected in parallel through a transparent conducting interlayer that acts as a common electrode to the two subcells [14]. In this structure, each material level must provide the same voltage and we can say that they are voltage matched, which is less restrictive than the current limitation of the two-terminal structures [15]. And the theoretical efficiency for three-terminal perovskite/Si tandem devices reaches $35 \%$, showing the potential for the design of efficient tandem devices [16].

However, the simpler strategy is employing a fourterminal architecture, wherein the top and bottom cells are electrically isolated from each other and the output power is extracted separately. This configuration does not require current (or voltage) matching of the two solar cells and, hence, enables independent optimization of the solar cell fabrication. For final assembly, both solar cells are simply mechanically stacked [17]. Since the four-terminal architecture requires at least three transparent electrodes, minimizing the parasitic absorption and manufacturing cost for these electrodes is therefore crucial for the viability of this tandem configuration [9]. For the four-terminal perovskite/ Si devices assembled by a perovskite top cell and Si bottom cell, many efforts were dedicated to search for an appropriate transparent electrode to replace the opaque metal rear contact normally used in PSCs. In most reports [17-26], the sputtered transparent-conductive-oxide (especially ITO) rear electrode has been commonly used, and the record overall efficiency of $26.4 \%$ has been achieved in the four-terminal devices with the perovskite top cell using the ITO/Au-finger electrode [18]. However, the sputtered ITO without postannealing $\left(>200^{\circ} \mathrm{C}\right)$ treatment usually shows the suboptimal conductivity, and the high kinetic energy of sputtered particles tends to damage the underlying spiro-OMeTAD or fullerene layers [19]; thus, it is essential to increase the thickness (or add the finger electrodes) to compensate the resistive loss and deposit the buffer layer to protect the organic charge transport layers $[18,20]$. Both of them increase the process complexity and the manufacturing cost.

Transparent silver (Ag) electrodes are promising candidates due to their advantages of simple evaporation process, facile process conditions, high conductivity, and relatively lower parasitic solar absorption than the gold film [27]. It has been proved in our previous works [28-31] and other reports [32-34] that the ultrathin Ag film with a suited optical coupling layer could meet the requirements of a transparent electrode. Our simulations [28] about bifacial semitransparent PSCs have shown that the maximum possible current density of a device illuminated from the Ag side rapidly increases with the decreasing Ag thickness, while it gradually decreases for the reverse illumination direction from the ITO side. This is due to the fact that the thinner the thickness, the higher the transmittance for Ag electrodes, but the conductive requirement limits the Ag thickness to its percolation threshold. To further improve the Ag transmittance, the strategy of the outer optical coupling layer [28-32] has been verified, while the reduced percolation limit to $6 \mathrm{~nm}$ is also possible by including a cooling stage during a high-rate evaporation of the $\operatorname{Ag}[35,36]$. In consequence, the semitransparent PSCs using the ultrathin Ag electrode may be the better top cell for the cost-effective four-terminal perovskite/Si devices. However, these devices are rarely reported.

In this work, the semitransparent perovskite solar cells (PSCs) have been fabricated with the structure of glass/ ITO/PEDOT:PSS/CH $\mathrm{CH}_{3} \mathrm{PbI}_{3-x} \mathrm{Cl}_{x} / \mathrm{PCBM} / \mathrm{BCP} /$ ultrathin$\mathrm{Ag} / \mathrm{MoO}_{3}$, where an $11 \mathrm{~nm} \mathrm{Ag} \mathrm{film} \mathrm{with} 10 \mathrm{~nm} \mathrm{MoO}$ optical coupling layer acts as the transparent electrode; the BCP interlayer is employed to align the energy levels at the PCBM/Ag interface; and this PSC can be illuminated from both the ITO and Ag sides. The resulting PSC shows a bifacial performance with a PCE of $13.38 \%$ from the ITO side and $8.34 \%$ from the Ag side with negligible current hysteresis. Furthermore, a four-terminal tandem cell was constructed by stacking an industrial low-bandgap Si bottom cell $(\mathrm{PCE}=14.2 \%)$ to broaden the spectral response of the perovskite top cell. The resulting perovskite/Si tandem cell obtained the overall efficiencies of $17.03 \%$ (ITO side) and $11.33 \%$ (Ag side), and the corresponding PCEs of the perovskite top cell have been increased by $27 \%$ and $39 \%$, respectively. Also, the PCE of tandem cell has exceeded that of the reference Si solar cells by about $20 \%$. This work provides an outlook to fabricate high-performance solar cells via the cost-effective pathway.

\section{Methods and Materials}

The planar structure of the four-terminal device in this work is shown in Figure 1. For the top cell, the $\mathrm{CH}_{3} \mathrm{NH}_{3} \mathrm{PbI}_{3-x} \mathrm{Cl}_{x}$ perovskite film is employed as the photoactive layer; the poly(3,4-ethylenedioxythiophene) poly(styrenesulfonate) (PEDOT:PSS) acts as a hole transport layer and the phenyl$\mathrm{C}_{61}$-butyric acid methyl ester (PCBM) plays the role of the electron transport layer; the ITO, the anode, and the Ag film are chosen as the semitransparent top cathode; the 


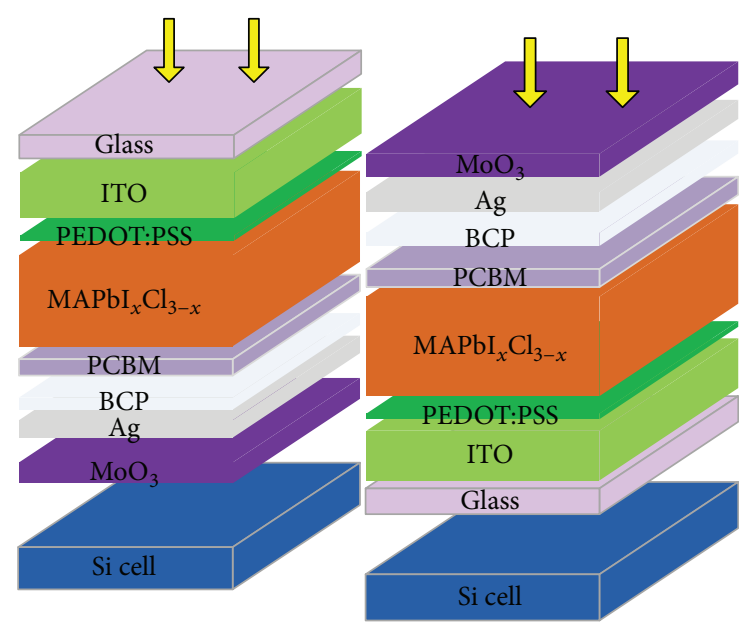

(a)

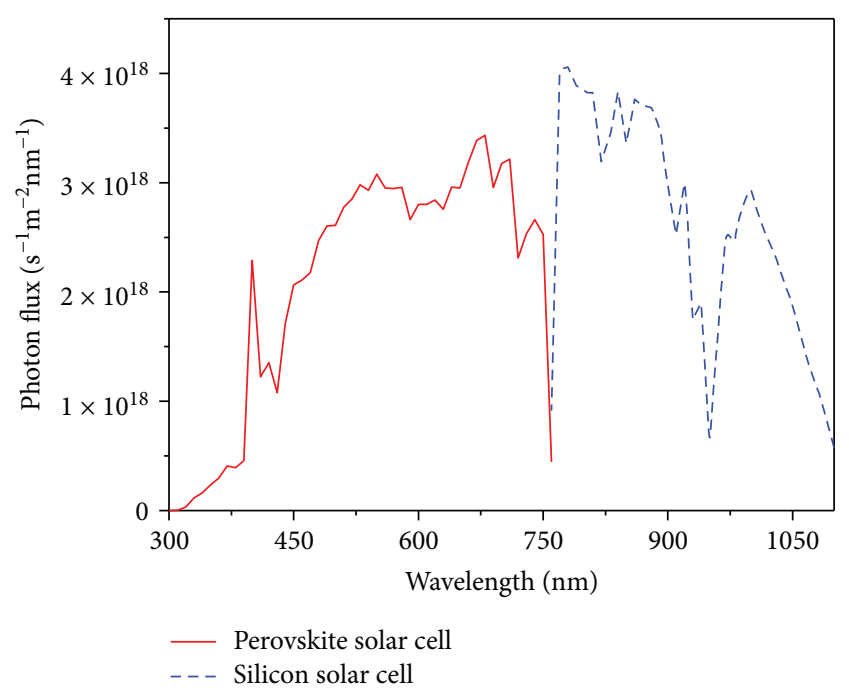

(b)

FIGURE 1: (a) Schematic diagrams of a perovskite/Si tandem cell illuminated from the ITO and Ag sides. (b) AM1.5G photon flux represents the spectral range that is effectively harvested by the perovskite top solar cell and the Si bottom cell.

molybdenum oxide $\left(\mathrm{MoO}_{3}\right)$ optical coupling layer is used to adjust the transmission and reflection of $\mathrm{Ag}$ electrode; and the bathocuproine (BCP) interfacial modifying layer is inserted to reduce the electron transport barrier at the $\mathrm{PCBM} / \mathrm{Ag}$ interface.

2.1. Device Fabrication. The planar heterojunction PSCs are fabricated as follows. First, the ITO-coated glass substrates were cleaned with detergent, DI water, acetone, and alcohol for $15 \mathrm{~min}$. And then they were treated by UV-OZONE for 20 minutes before device fabrication. A layer of PEDOT:PSS (Clevios P VP Al 4083) was spun coated on an ITO substrate (around $2 \times 2.5 \mathrm{~cm}^{2}$ in size, $10 \Omega$ per square) at $7000 \mathrm{rpm}$ for 40 seconds followed by annealing at $150^{\circ} \mathrm{C}$ for 15 minutes on a hot plate. Then, the substrates were transferred into a glove box filled with nitrogen. $\mathrm{CH}_{3} \mathrm{NH}_{3} \mathrm{PbI}_{3-x} \mathrm{Cl}_{x}$ perovskite films were deposited by spin coating a solution containing $1.26 \mathrm{M}$ $\mathrm{PbI}_{2}$ (99.999\%, Sigma) and 0.14 $\mathrm{M} \mathrm{PbCl}_{2}$ (99.999\%, Sigma) and $1.35 \mathrm{M} \mathrm{CH}_{3} \mathrm{NH}_{3} \mathrm{I}(99.8 \%$, Dyesol) in a cosolvent of DMSO:GBL (3:7 vol. ratio, Sigma). The spin coater was started at a rotation speed of $1000 \mathrm{rpm}$ for 15 seconds and $5000 \mathrm{rpm}$ for another 45 seconds. $350 \mu \mathrm{l}$ toluene $(99.8 \%$, Sigma-Aldrich) was added quickly at 40 seconds after the start of the spin coating process. After the spin coating, the samples were then solvent annealed on the hotplate at $100^{\circ} \mathrm{C}$ for $20 \mathrm{~min}$ to form the perovskite layer with the thickness about $300 \mathrm{~nm}$. In detail, the sample was put on the top of the hot plate and covered by a glass petri dish. Around $40 \mu \mathrm{l}$ of IPA solvent was dripped around the substrates during the thermal annealing process so that the solvent vapor could make contact. This solvent annealing process can improve the film crystalline quality, and the mechanism was discussed in our previous work [37]. Then, the $20 \mathrm{mg} / \mathrm{ml}$ chlorobenzene $(99.8 \%$, Sigma) solution of PCBM (98\%, Nano-C) was spin-coated at $2000 \mathrm{rpm}$ for 40 seconds. The $10 \mathrm{~nm} \mathrm{BCP}$ $(0.5 \mathrm{mg} / \mathrm{ml}$ in IPA) was coated at $6000 \mathrm{rpm}$ for 40 seconds. Next, the samples were transferred into a metal evaporation chamber, and $11 \mathrm{~nm}$ thick Ag was deposited under high vacuum $\left(<4 \times 10^{-4} \mathrm{~Pa}\right)$. Finally, the $10 \mathrm{~nm}$ thick $\mathrm{MoO}_{3}(99.9 \%$, Aldrich) was evaporated on the Ag electrode. And the fabricated device shows an active area of $7 \mathrm{~mm}^{2}$. The bottom silicon cell with an efficiency of $14.2 \%$ is provided by the Huanghe Hydropower Solar Industry Technology Co. Ltd.

2.2. Device Characterization. The photovoltaic performances of PSCs were measured by using a Keithley 2400 source meter under the simulated AM 1.5G (1 sun, $100 \mathrm{~mW} / \mathrm{cm}^{2}$ ) from a sunlight simulator (SaneiElectric, XES-300T1). The illumination intensity was calibrated by the National Renewable Energy Laboratory (NREL) using a reference Si solar cell. The incident photo-to-current conversion efficiencies (IPCEs) were measured by the quantum efficiency measurement system (SCS10-X150, Zolix Instruments Co. Ltd.) for all unencapsulated PSCs, and all the measurements were performed under ambient atmosphere at room temperature. A UV-visible spectrophotometer (PerkinElmer Lambda 950) was used to characterize the transmittance and reflectance spectra of different samples. The film morphology was characterized by a JSM-7800F extreme-resolution analytical field emission scanning electron microscope (SEM). And the X-ray diffraction (XRD) patterns were obtained from an $\mathrm{X}$-ray diffractometer (D8 Advance, Bruker, Germany).

\section{Results and Discussions}

Figure 1 shows the architecture of four-terminal perovskite/ $\mathrm{Si}$ tandem devices, where the $\mathrm{CH}_{3} \mathrm{NH}_{3} \mathrm{PbI}_{3-x} \mathrm{Cl}_{x}$ perovskite solar cell acts as the top cell and the commercial Si solar cell serves as the bottom cell, and a broadened spectral response can be observed from Figure 1(b). To obtain higher overall PCE for the tandem device, the efficient semitransparent perovskite top cell was first developed. Here, our top cell adopted the structure of glass/ITO/ PEDOT:PSS/CH $\mathrm{CH}_{3} \mathrm{PbI}_{3-x} \mathrm{Cl}_{x} / \mathrm{PCBM} / \mathrm{BCP} /$ ultrathin-Ag/ 


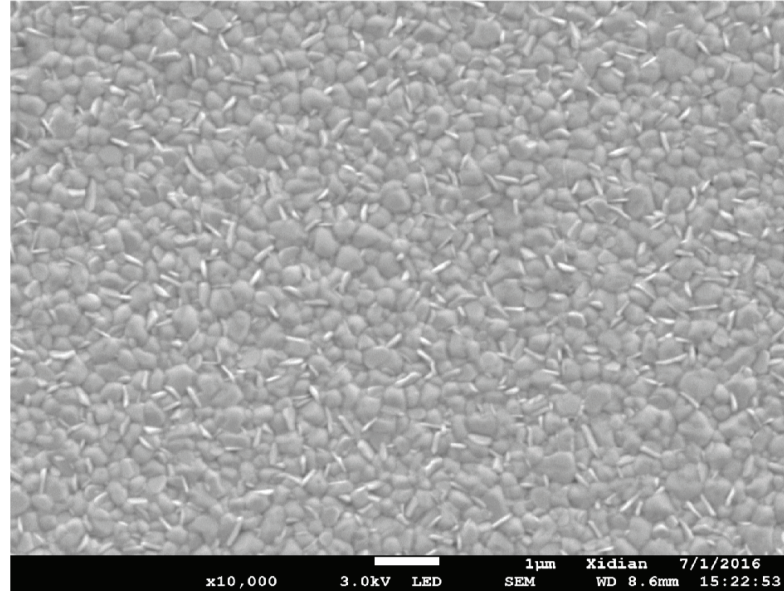

(a)

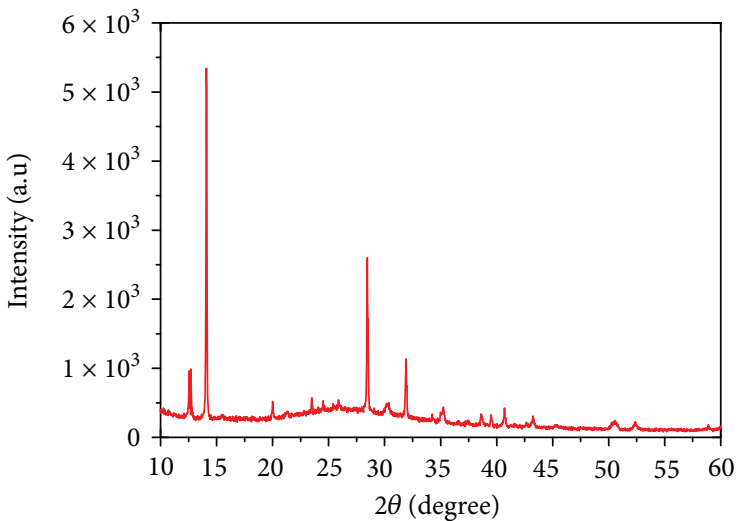

(b)

FIGURE 2: SEM image (a) and XRD patterns (b) of $\mathrm{CH}_{3} \mathrm{NH}_{3} \mathrm{PbI}_{3-x} \mathrm{Cl}_{x}$ perovskite films via IPA solvent annealing.

$\mathrm{MoO}_{3}$. In details, an ultrathin $\mathrm{Ag}$ film of $11 \mathrm{~nm}$ is chosen as the transparent cathode as the percolation threshold of Ag thickness in our laboratory is $11 \mathrm{~nm}$ at which the acceptable transmittance and conductivity can be obtained [38]. To further improve the optical properties of the Ag electrode, the $10 \mathrm{~nm}$ thick $\mathrm{MoO}_{3}$ optical coupling layer is evaporated to act as the antireflector which enhances the transmittance of the Ag electrode; it could also reflect some of the transmitted light back into the perovskite and improve the light absorption in the top cell. These optical mechanisms have been proved in our previous calculations and experimental reports [28]. To enhance the electron collection ability of the Ag electrode, a low-work-function BCP modifying layer is inserted between the PCBM and Ag to align the energy levels and decrease the electron transport barrier at the $\mathrm{PCBM} / \mathrm{Ag}$ interface, which has been approved as an effective way to improve the current density and fill factor of PSCs.

In particular, the introduction of chlorine could retard the crystallization of perovskite to improve the perovskite quality and increase the carrier diffusion length and the charge mobility [39]. Combining the isopropyl alcohol (IPA) solvent annealing process, the SEM image of the resulting $\mathrm{CH}_{3} \mathrm{NH}_{3} \mathrm{PbI}_{3-x} \mathrm{Cl}_{x}$ film in Figure 2(a) shows a compact and smooth surface, increased average grain size, and obviously reduced pin holes. Also in Figure 2(b), the XRD diffraction peaks around $14.21^{\circ}, 28.51^{\circ}$, and $31.88^{\circ}$ are assigned to the (110), (220), and (310) lattice planes, respectively, of the tetragonal perovskite structure, which indicates the formation of perovskite film. The XRD peak at $12.7^{\circ}$ is corresponding to the cubic $\mathrm{PbI}_{2}[40,41]$; this is a very typical observation for the incomplete conversion into the photoactive black phase in the mixed perovskite composition. Based on the high-quality perovskite film and four-terminal architecture, the performance of fabricated devices are discussed as follows.

Due to the bifacial feature of the semitransparent perovskite top cell, its performance should be divided into two cases according to the different illumination directions-the ITO side and the Ag side (see Figure 1(a)). At first, for the tandem device illuminated from the ITO side, the JV characteristics and photovoltaic parameters can be found in Figure 3(a) and Table 1. It is clear that the semitransparent $\mathrm{CH}_{3} \mathrm{NH}_{3} \mathrm{PbI}_{3-x} \mathrm{Cl}_{x}$ top cell achieves a PCE of $13.38 \%$, with $J_{\mathrm{SC}}=18.21 \mathrm{~mA} / \mathrm{cm}^{2}, V_{\mathrm{OC}}=0.98 \mathrm{~V}$, and $\mathrm{FF}=0.74$, which is comparable to that of the reference perovskite device with an opaque $\mathrm{Ag}(100 \mathrm{~nm})$ electrode. Simultaneously, no obvious current hysteresis has been observed, as the PCE only displays a small variation from $13.10 \%$ to $13.38 \%$ for the opposite voltage sweep directions. This performance is much better than that of the PSC with only a Ag transparent electrode [28]. While in the tandem architecture, also shown in Figure 3(a) and Table 1, the bottom Si cell obtains a PCE of $3.65 \%$ with $J_{\mathrm{SC}}=9.17 \mathrm{~mA} / \mathrm{cm}^{2}, V_{\mathrm{OC}}=0.56 \mathrm{~V}$, and $\mathrm{FF}=0.71$; the PCE and $J_{\mathrm{SC}}$ of the bottom cell are much lower than those of the original Si cell $\left(14.2 \%\right.$ and $36 \mathrm{~mA} / \mathrm{cm}^{2}$, resp.), which indirectly demonstrates the efficient light absorption in the perovskite top cell. Then, the overall efficiency of this four-terminal tandem cell reaches $17.03 \%$, which is $27 \%$ higher than that of the top cell and $20 \%$ higher than that of the original Si solar cell. Therefore, the mechanically stacked perovskite/Si tandem cell provides a simple and feasible way to further improve the PCE of both perovskite and $\mathrm{Si}$ solar cells. On the other hand, the perovskite top cell illuminated from the Ag side obtained a PCE of $8.34 \%$ with $J_{\mathrm{SC}}=12.0 \mathrm{~mA} / \mathrm{cm}^{2}, V_{\mathrm{OC}}=0.94 \mathrm{~V}$, and $\mathrm{FF}=0.74$, and the PCE only displays a small variation from $8.07 \%$ to $8.34 \%$ for the opposite voltage sweep directions. While in the tandem architecture, the Si bottom cell achieves a PCE of $3.26 \%$ (see Figure 3(b) and Table 1); thus, the overall efficiency of the tandem cell here is $11.60 \%$, which is $39 \%$ higher than that of the perovskite top cell.

It is suggested that the obviously improved efficiency for the perovskite/Si tandem cell comes from the broadened spectral response range and increased photovoltaic 


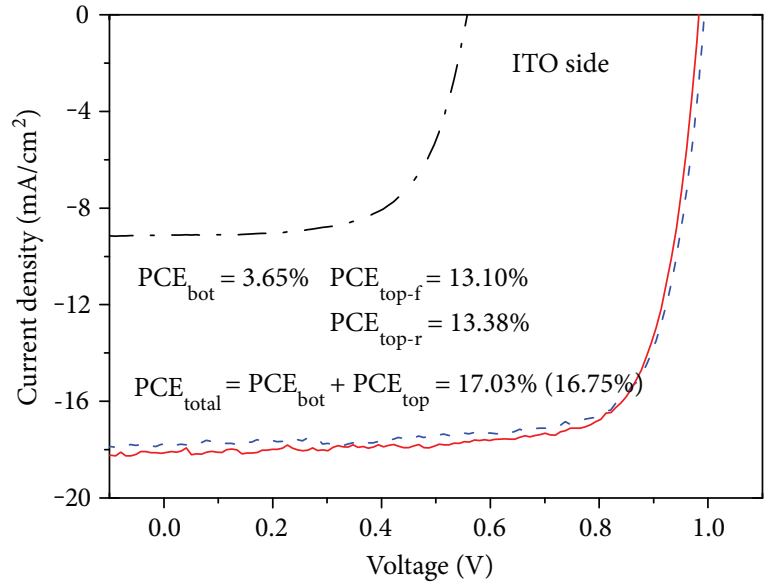

Perovskite top cell

- - Si bottom cell

- - Forward scan

— Reverse scan

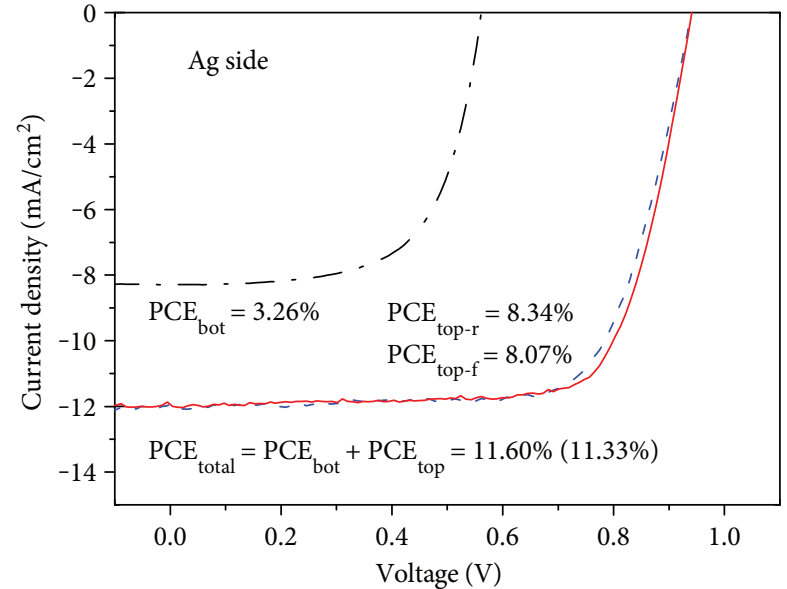

Perovskite top cell

- - Si bottom cell

- - Forward scan

_ Reverse scan

(a)

(b)

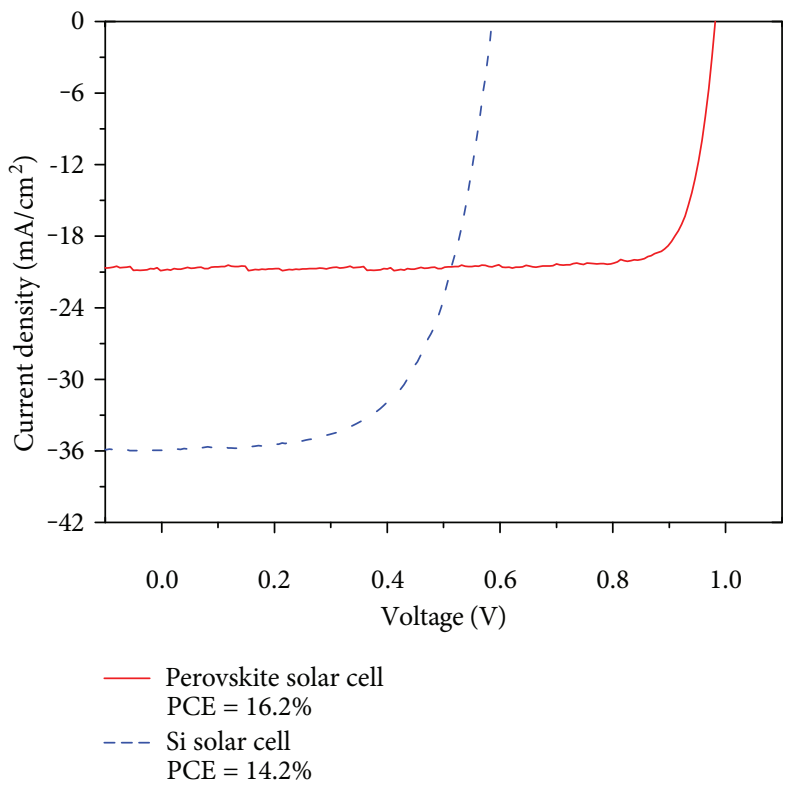

(c)

Figure 3: JV characteristics of the perovskite top cell and Si bottom cell illuminated from (a) the ITO side and (b) the Ag film side using reverse $(1.1 \mathrm{~V}$ to $-0.2 \mathrm{~V})$ and forward $(-0.2 \mathrm{~V}$ to $1.1 \mathrm{~V})$ scan measurement. (c) JV characteristics of reference opaque perovskite and Si solar cells.

conversion in the infrared region. To confirm this suggestion, the wavelength-dependent IPCE curves of the perovskite top cell, Si bottom cell, and original Si solar cell are displayed in Figure 4(a). It is clear that the perovskite top cell mainly responds to the visible region from 300 to $800 \mathrm{~nm}$, the maximum IPCE of about $77 \%$ at $580 \mathrm{~nm}$ is obtained, and the integrated $J_{\mathrm{SC}}$ of $18.02 \mathrm{~mA} / \mathrm{cm}^{2}$ is very close to the measured $J_{\mathrm{SC}}$ in the JV characteristic. Then, the reference silicon solar cell shows the efficient photovoltaic conversion in the wavelength range from 300 to $1100 \mathrm{~nm}$ and stable IPCE maxima in a wide spectral range, and the integrated $J_{\mathrm{SC}}$ is as high as $35.6 \mathrm{~mA} / \mathrm{cm}^{2}$. While in the tandem device, the Si bottom cell mainly responds to the spectra range from 500 to $1100 \mathrm{~nm}$, which is well consistent with the optical transmittance of the perovskite top cell shown in Figure 4(b). At the same time, the low reflection at relatively short wavelengths corresponds to the efficient light harvest in the perovskite top cell, and the higher reflection at long wavelengths is partly responsible for the decreased performance for the Si bottom cell. It should be noted that there is still room for performance improvement of the semitransparent perovskite top cell, and even at the limit efficiency, the simple four-terminal perovskite/Si tandem architecture can still be used to 
TABle 1: Photovoltaic parameters of the perovskite top cell and Si bottom cell, with reference to opaque perovskite and Si solar cells. The overall efficiency is the sum of PCE for the corresponding top and bottom cells.

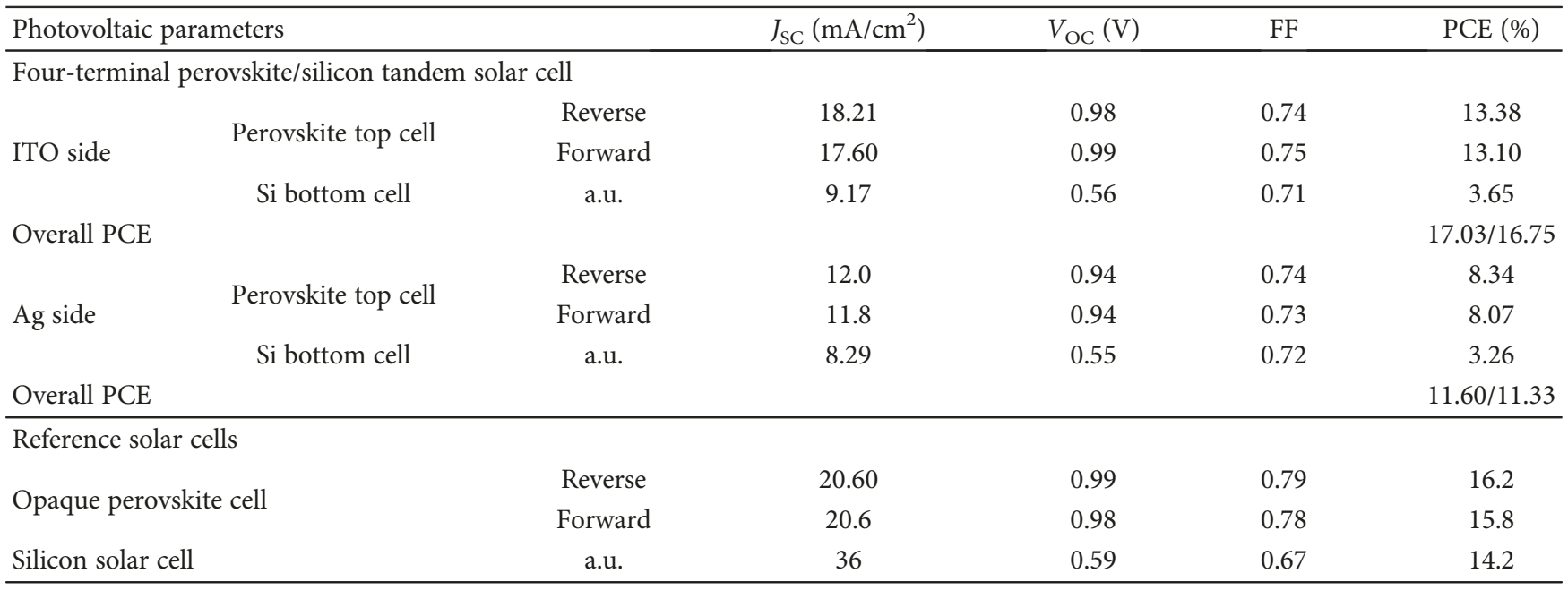

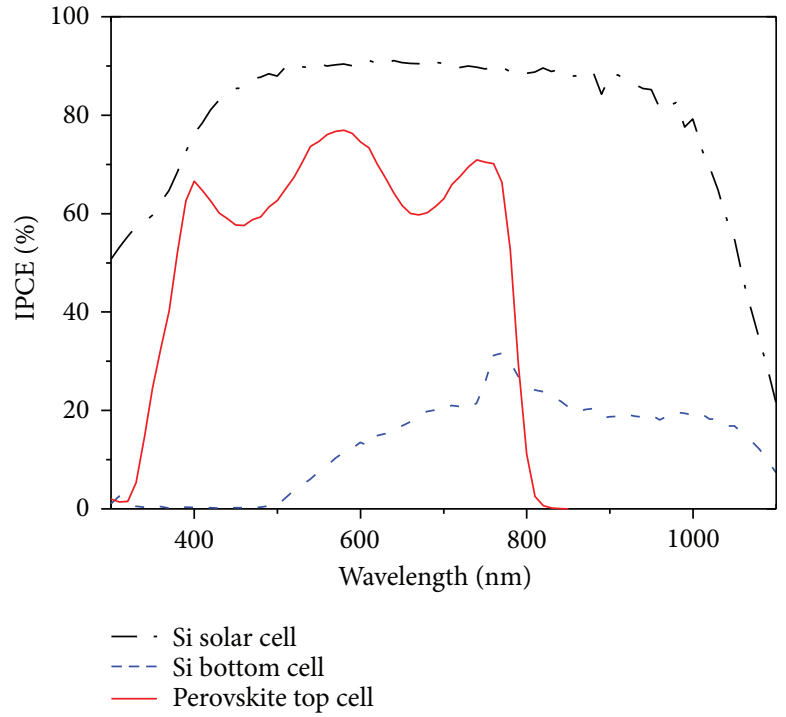

(a)

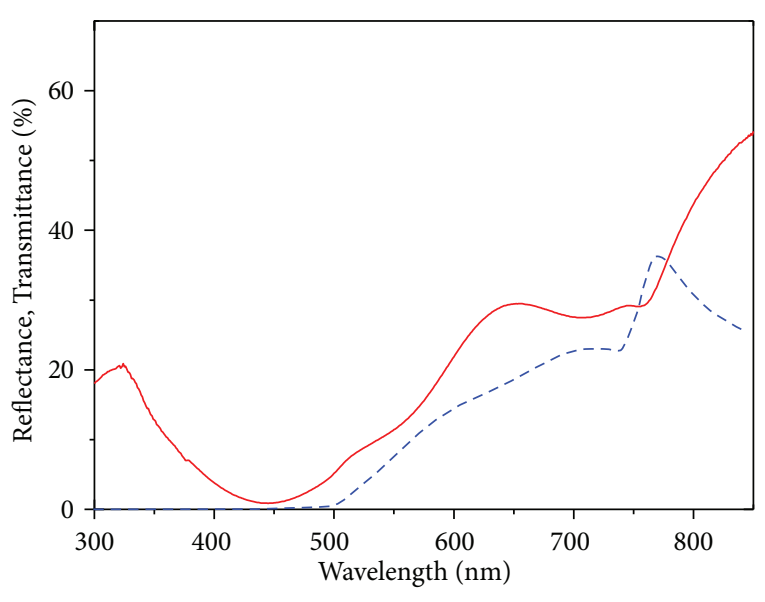

Perovskite top cell

Reflectance

(b)

FIGURE 4: (a) IPCE curves for the perovskite top cell, Si bottom cell, and reference Si solar cell, and the integrated $J_{\text {SC }}$ from IPCEs are 18.02, 9.12, and $36.00 \mathrm{~mA} / \mathrm{cm}^{2}$, respectively. (b) Transmittance and reflectance of the semitransparent perovskite top cell.

enhance the photovoltaic conversion. Thus, in the future works, not only the perovskite top cell but also the tandem architecture should be further investigated and designed to pursue the maximum overall efficiency for the perovskite/ Si tandem cells.

\section{Conclusions}

In summary, the efficient semitransparent $\mathrm{CH}_{3} \mathrm{NH}_{3} \mathrm{PbI}_{3-x} \mathrm{Cl}_{x}$ perovskite solar cell using a $\mathrm{Ag}$ transparent electrode was realized by employing the $\mathrm{MoO}_{3}$ optical coupling layer and BCP interfacial layer. The resulting PCE is $13.38 \%$ when the PSC is illuminated from the ITO side and the PCE of 8.34\% from the Ag side, and no obvious current hysteresis can be observed. Furthermore, by stacking a Si bottom cell under the perovskite top cell to form a four-terminal perovskite/Si tandem architecture, the spectral response range has been broadened, and the overall PCEs of $17.03 \%$ (ITO side) and $11.60 \%$ (Ag side) can be obtained, which are $27 \%$ and $39 \%$ higher, respectively, than those of the perovskite top cell. Also, the PCE of the tandem cell has exceeded that of the reference Si solar cells by about $20 \%$. Therefore, this work provides a simple and cost-effective pathway to fabricate high-performance solar cells.

\section{Conflicts of Interest}

The authors declare that they have no conflicts of interest. 


\section{Authors' Contributions}

Shangzheng Pang and Dazheng Chen contributed equally to this work.

\section{Acknowledgments}

This work was partly financially supported by the National Natural Science Foundation of China under Grants 61334002 and 61106063, the Natural Science Foundation of Shaanxi under Grant 2017JQ6014, the Fundamental Research Funds for the Central Universities (Grant no. JB151406), and a Class General Financial Grant from the China Postdoctoral Science Foundation (Grant no. 2016M602771). The authors would also like to thank Huanghe Hydropower Solar Industry Technology Co. Ltd. for providing the silicon solar cell samples.

\section{References}

[1] J.-P. Correa-Baena, M. Saliba, T. Buonassisi et al., "Promises and challenges of perovskite solar cells," Science, vol. 358, no. 6364, pp. 739-744, 2017.

[2] D. Zhou, T. Zhou, Y. Tian, X. Zhu, and Y. Tu, "Perovskitebased solar cells: materials, methods, and future perspectives," Journal of Nanomaterials, vol. 2018, Article ID 8148072, 15 pages, 2018.

[3] S. D. Stranks, G. E. Eperon, G. Grancini et al., "Electron-hole diffusion lengths exceeding 1 micrometer in an organometal trihalide perovskite absorber," Science, vol. 342, no. 6156, pp. 341-344, 2013.

[4] J. H. Noh, S. H. Im, J. H. Heo, T. N. Mandal, and S. I. Seok, "Chemical management for colorful, efficient, and stable inorganic-organic hybrid nanostructured solar cells," Nano Letters, vol. 13, no. 4, pp. 1764-1769, 2013.

[5] R. E. Brandt, V. Stevanović, D. S. Ginley, and T. Buonassisi, "Identifying defect-tolerant semiconductors with high minority-carrier lifetimes: beyond hybrid lead halide perovskites," MRS Communications, vol. 5, no. 2, pp. 265-275, 2015.

[6] J. P. Correa-Baena, W. Tress, K. Domanski et al., "Identifying and suppressing interfacial recombination to achieve high open-circuit voltage in perovskite solar cells," Energy \& Environmental Science, vol. 10, no. 5, pp. 1207-1212, 2017.

[7] A. Kojima, K. Teshima, Y. Shirai, and T. Miyasaka, "Organometal halide perovskites as visible-light sensitizers for photovoltaic cells," Journal of the American Chemical Society, vol. 131, no. 17, pp. 6050-6051, 2009.

[8] "NREL efficiency chart," April 2016, https://www.nrel.gov/pv/ assets/images/efficiency-chart.png.

[9] J. Werner, B. Niesen, and C. Ballif, "Perovskite/silicon tandem solar cells: marriage of convenience or true love story? - An overview," Advanced Materials Interfaces, vol. 5, no. 1, article 1700731, 2018.

[10] S. Albrecht, M. Saliba, J. P. Correa Baena et al., "Monolithic perovskite/silicon-heterojunction tandem solar cells processed at low temperature," Energy \& Environmental Science, vol. 9, no. 1, pp. 81-88, 2016.

[11] J. P. Mailoa, C. D. Bailie, E. C. Johlin et al., "A 2-terminal perovskite/silicon multijunction solar cell enabled by a silicon tunnel junction," Applied Physics Letters, vol. 106, no. 12, article 121105, 2015.
[12] J. Werner, C.-H. Weng, A. Walter et al., "Efficient monolithic perovskite/silicon tandem solar cell with cell area $>1 \mathrm{~cm}^{2}$," The Journal of Physical Chemistry Letters, vol. 7, no. 1, pp. 161-166, 2016.

[13] K. A. Bush, A. F. Palmstrom, Z. J. Yu et al., "23.6\%-efficient monolithic perovskite/silicon tandem solar cells with improved stability," Nature Energy, vol. 2, no. 4, article 17009, 2017.

[14] S. Sista, Z. Hong, M.-H. Park, Z. Xu, and Y. Yang, "Highefficiency polymer tandem solar cells with three-terminal structure," Advanced Materials, vol. 22, no. 8, pp. E77E80, 2010.

[15] J. C. Jimeno, R. Gutierrez, V. Fano et al., "A 3 terminal parallel connected silicon tandem solar cell," Energy Procedia, vol. 92, pp. 644-651, 2016.

[16] G. W. P. Adhyaksa, E. Johlin, and E. C. Garnett, "Nanoscale back contact perovskite solar cell design for improved tandem efficiency," Nano Letters, vol. 17, no. 9, pp. 5206-5212, 2017.

[17] M. Jaysankar, W. Qiu, M. van Eerden et al., "Four-terminal perovskite/silicon multijunction solar modules," Advanced Energy Materials, vol. 7, no. 15, article 1602807, 2017.

[18] T. Duong, Y. Wu, H. Shen et al., "Rubidium multication perovskite with optimized bandgap for perovskite-silicon tandem with over 26\% efficiency," Advanced Energy Materials, vol. 7, no. 14, article 1700228, 2017.

[19] P. Löper, S.-J. Moon, S. Martín de Nicolas et al., "Organicinorganic halide perovskite/crystalline silicon four-terminal tandem solar cells," Physical Chemistry Chemical Physics, vol. 17, no. 3, pp. 1619-1629, 2015.

[20] K. A. Bush, C. D. Bailie, Y. Chen et al., "Thermal and environmental stability of semi-transparent perovskite solar cells for tandems enabled by a solution-processed nanoparticle buffer layer and sputtered ITO electrode," Advanced Materials, vol. 28, no. 20, pp. 3937-3943, 2016.

[21] M. Anaya, G. Lozano, M. E. Calvo, and H. Miguez, "ABX perovskites for tandem solar cells," Joule, vol. 1, no. 4, pp. 769-793, 2017.

[22] T. Duong, N. Lal, D. Grant et al., "Semitransparent perovskite solar cell with sputtered front and rear electrodes for a fourterminal tandem," IEEE Journal of Photovoltaics, vol. 6, no. 3, pp. 679-687, 2016.

[23] J. Werner, G. Dubuis, A. Walter et al., "Sputtered rear electrode with broadband transparency for perovskite solar cells," Solar Energy Materials and Solar Cells, vol. 141, pp. 407-413, 2015.

[24] J. Werner, S. J. Moon, P. Löper et al., “Towards ultra-high efficient photovoltaics with perovskite/crystalline silicon tandem devices," in 31st European Photovoltaic Solar Energy Conference and Exhibition, pp. 6-11, Hamburg, Germany, 2015.

[25] D. P. McMeekin, G. Sadoughi, W. Rehman et al., "A mixedcation lead mixed-halide perovskite absorber for tandem solar cells," Science, vol. 351, no. 6269, pp. 151-155, 2016.

[26] J. Werner, L. Barraud, A. Walter et al., "Efficient near-infraredtransparent perovskite solar cells enabling direct comparison of 4-terminal and monolithic perovskite/silicon tandem cells," ACS Energy Letters, vol. 1, no. 2, pp. 474-480, 2016.

[27] N. Ahmad, J. Stokes, N. A. Fox, M. Teng, and M. J. Cryan, "Ultra-thin metal films for enhanced solar absorption," Nano Energy, vol. 1, no. 6, pp. 777-782, 2012.

[28] S. Pang, D. Chen, C. Zhang et al., "Efficient bifacial semitransparent perovskite solar cells with silver thin film electrode," 
Solar Energy Materials and Solar Cells, vol. 170, pp. 278-286, 2017.

[29] S. Pang, X. Li, H. Dong et al., "Efficient bifacial semitransparent perovskite solar cells using $\mathrm{Ag} / \mathrm{V}_{2} \mathrm{O}_{5}$ as transparent anodes," ACS Applied Materials \& Interfaces, vol. 10, no. 15, pp. 12731-12739, 2018.

[30] D. Chen, H. Xi, C. Zhang et al., "Simulation study toward highperformance transparent-conductive-oxide free perovskite solar cells using metal microcavity and optical coupling layer," IEEE Photonics Journal, vol. 10, no. 2, article 8400209, 2018.

[31] N. Li, D. Chen, C. Zhang et al., "High-performance lowbandgap polymer solar cells with optical microcavity employing ultrathin Ag film electrode," IEEE Photonics Journal, vol. 8, no. 6, pp. 1-12, 2016

[32] C. Hanmandlu, C.-Y. Chen, K. M. Boopathi, H.-W. Lin, C.-S. Lai, and C.-W. Chu, "Bifacial perovskite solar cells featuring semitransparent electrodes," ACS Applied Materials \& Interfaces, vol. 9, no. 38, pp. 32635-32642, 2017.

[33] H. Lu, J. Sun, H. Zhang, S. Lu, and W. C. H. Choy, "Roomtemperature solution-processed and metal oxide-free nanocomposite for the flexible transparent bottom electrode of perovskite solar cells," Nanoscale, vol. 8, no. 11, pp. 59465953, 2016.

[34] C. Roldán-Carmona, O. Malinkiewicz, R. Betancur et al., "High efficiency single-junction semitransparent perovskite solar cells," Energy \& Environmental Science, vol. 7, no. 9, pp. 2968-2973, 2014.

[35] N. P. Sergeant, A. Hadipour, B. Niesen et al., "Design of transparent anodes for resonant cavity enhanced light harvesting in organic solar cells," Advanced Materials, vol. 24, no. 6, pp. 728-732, 2012.

[36] R. Betancur, P. Romero-Gomez, A. Martinez-Otero, X. Elias, M. Maymo, and J. Martorell, "Transparent polymer solar cells employing a layered light-trapping architecture," Nature Photonics, vol. 7, no. 12, pp. 995-1000, 2013.

[37] X. Sun, C. Zhang, J. Chang et al., "Mixed-solvent-vapor annealing of perovskite for photovoltaic device efficiency enhancement," Nano Energy, vol. 28, pp. 417-425, 2016.

[38] Z. Wang, C. Zhang, R. Gao et al., "Improvement of transparent silver thin film anodes for organic solar cells with a decreased percolation threshold of silver," Solar Energy Materials and Solar Cells, vol. 127, pp. 193-200, 2014.

[39] J. Mo, C. Zhang, J. Chang et al., "Enhanced efficiency of planar perovskite solar cells via a two-step deposition using DMF as an additive to optimize the crystal growth behavior," Journal of Materials Chemistry A, vol. 5, no. 25, pp. 13032-13038, 2017.

[40] Q. Chen, H. Zhou, T. B. Song et al., "Controllable self-induced passivation of hybrid lead iodide perovskites toward high performance solar cells," Nano Letters, vol. 14, no. 7, pp. 41584163, 2014.

[41] L. Wang, C. McCleese, A. Kovalsky, Y. Zhao, and C. Burda, "Femtosecond time-resolved transient absorption spectroscopy of $\mathrm{CH}_{3} \mathrm{NH}_{3} \mathrm{PbI}_{3}$ perovskite films: evidence for passivation effect of $\mathrm{PbI}_{2}$," Journal of the American Chemical Society, vol. 136, no. 35, pp. 12205-12208, 2014. 


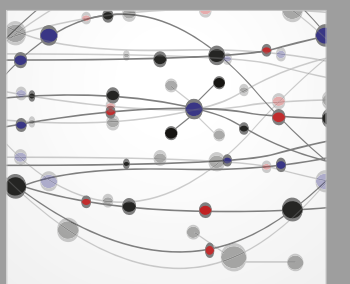

The Scientific World Journal
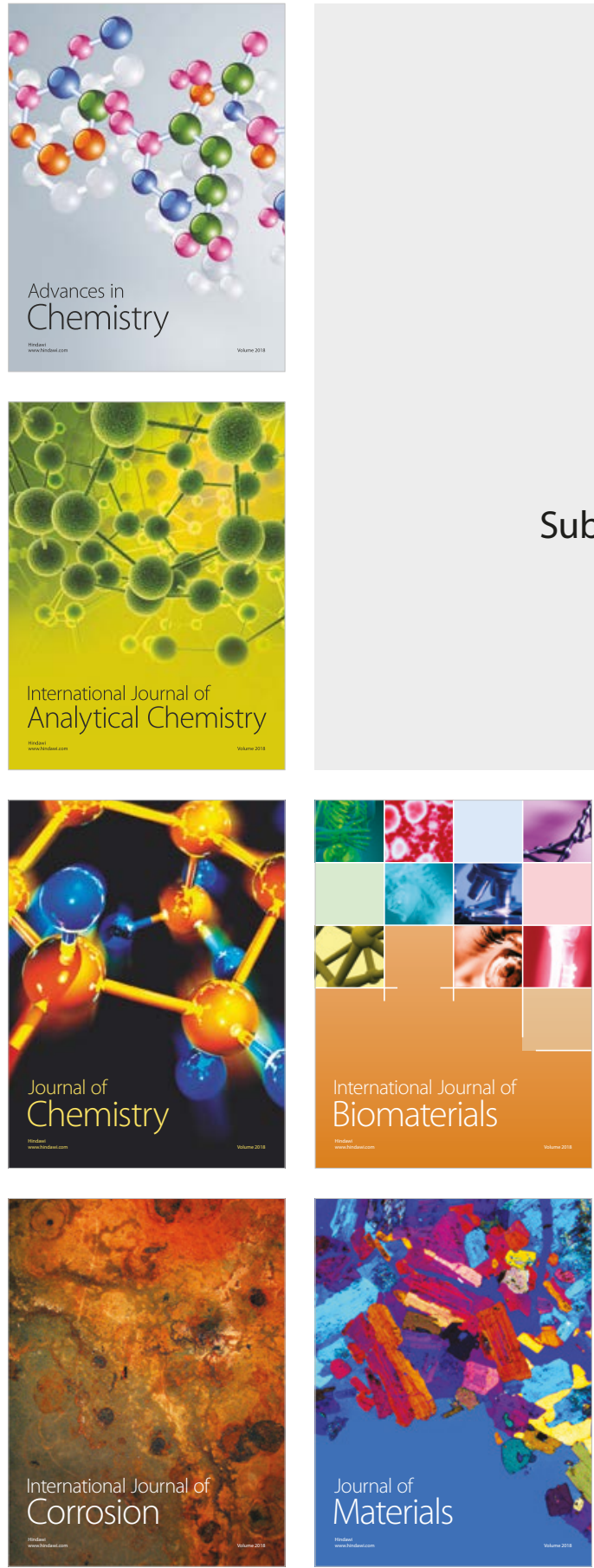

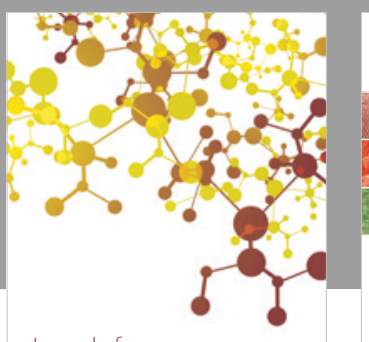

Journal of

Applied Chemistry
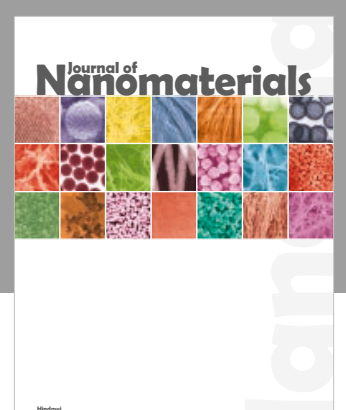

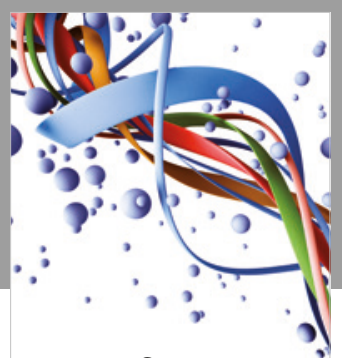

Scientifica

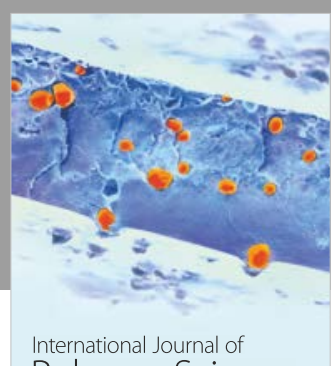

Polymer Science

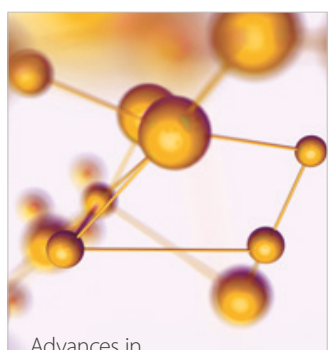

Physical Chemistry
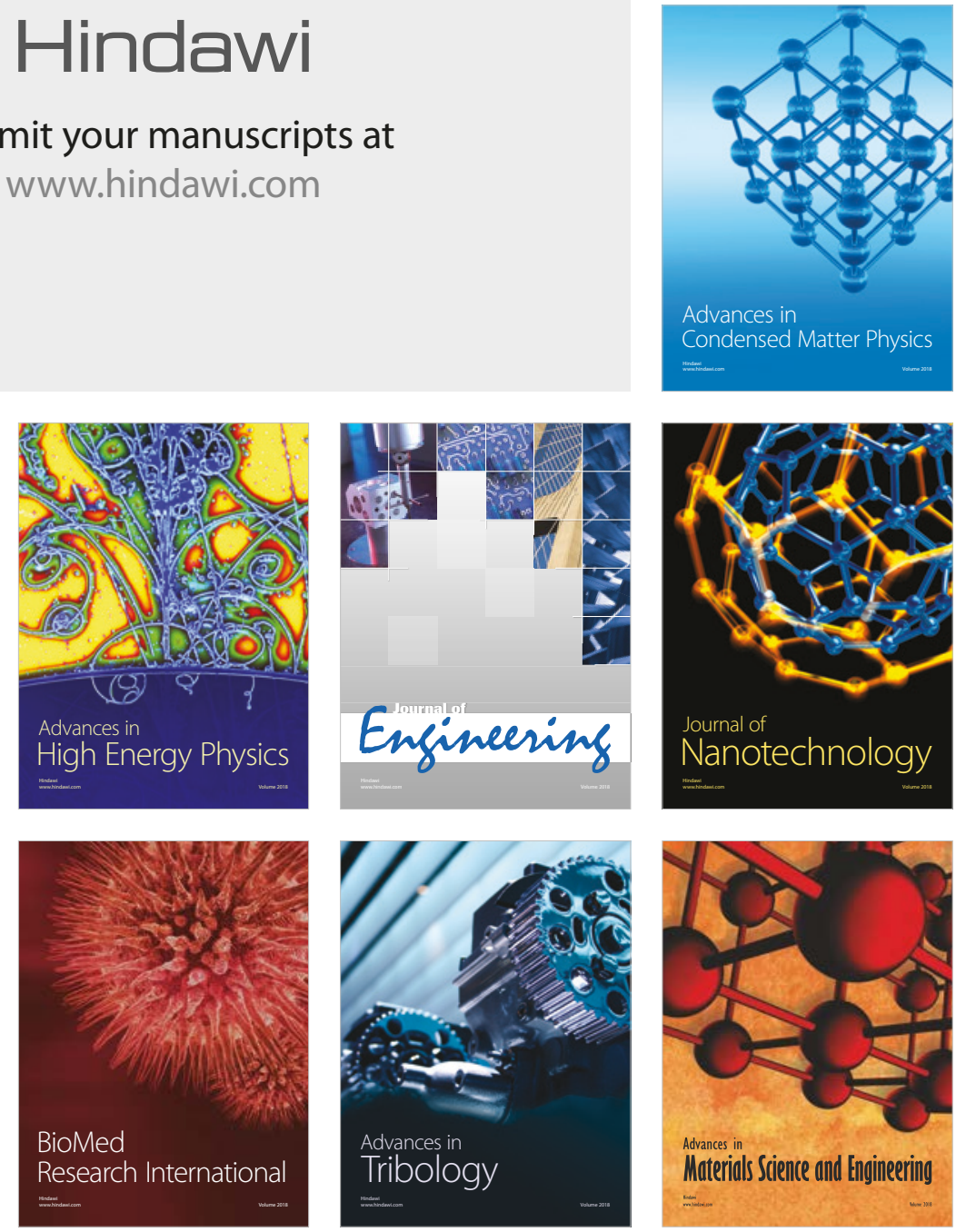